\title{
Reliability of breeding values for feed intake and feed efficiency traits in dairy cattle: When dry matter intake recordings are sparse under different scenarios
}

\author{
E. Negussie, ${ }^{1 *}$ T. Mehtiö, ${ }^{1}$ P. Mäntysaari, ${ }^{1}$ P. Løvendahl, ${ }^{2}$ E. A. Mäntysaari, ${ }^{1}$ and M. H. Lidauer ${ }^{1}$ \\ ${ }^{1}$ Natural Resources Institute Finland (Luke), Myllytie 1, 31600, Jokioinen, Finland \\ ${ }^{2}$ Department of Molecular Biology and Genetics, Aarhus University, DK-8830 Tjele, Denmark
}

\section{ABSTRACT}

Currently, routine recordings of dry matter intake (DMI) in commercial herds are practically nonexistent. Recording DMI from commercial herds is a prerequisite for the inclusion of feed efficiency $(\mathrm{FE})$ traits in dairy cattle breeding goals. To develop future on-farm phenotyping strategies, recording strategies that are low cost and less demanding logistically and that give relatively accurate estimates of the animal's genetic merit are therefore needed. The objectives of this study were (1) to estimate genetic parameters for daily DMI and FE traits and use the estimated parameters to simulate daily DMI phenotypes under different DMI recording scenarios (SCN) and (2) to use the simulated data to estimate for different scenarios the associated reliability of estimated breeding value and accuracies of genomic prediction for varying sizes of reference populations. Five on-farm daily DMI recording scenarios were simulated: once weekly (SCN1), once monthly (SCN2), every 2 mo (SCN3), every 3 mo (SCN4), and every 4 mo (SCN5). To estimate reliability of estimated breeding values, DMI and FE observations and true breeding values were simulated based on variance components estimated for daily observations of Nordic Red cows. To emulate realistic on-farm recording, 5 data set replicates, each with 36,037 DMI and FE records, were simulated for real pedigree and data structure of 789 Holstein cows. Observations for the 5 DMI recording scenarios were generated by discarding data in a step-wise manner from the full simulated data per the scenario's definitions. For each of these scenarios, reliabilities were calculated as correlation between the true and estimated breeding values. Variance components and genetic parameters were estimated for daily DMI, residual feed intake (RFI), and energy conversion efficiency (ECE) fitting the random regression

Received November 20, 2018.

Accepted March 29, 2019 .

*Corresponding author: enyew.negussie@luke.fi model. Data for variance components were from 227 primiparous Nordic Red dairy cows covering 8 to $280 \mathrm{~d}$ in milk. Lactation-wise heritability for DMI, RFI, and ECE was $0.33,0.12$, and 0.32 , respectively, and daily heritability estimates during lactation ranged from 0.18 to $0.45,0.08$ to 0.32 , and 0.08 to 0.45 for DMI, RFI, and ECE, respectively. Genetic correlations for DMI between different stages of lactation ranged from -0.50 to 0.99 . The comparison of different on-farm DMI recording scenarios indicated that adopting a less-frequent recording scenario ( $\mathrm{SCN} 3$ ) gave a similar level of accuracy as SCN1 when 17 more daughters are recorded per sire over the 46 needed for SCN1. Such a strategy is less demanding logistically and is low cost because fewer observations need to be collected per animal. The accuracy of genomic predictions associated with the 5 recording scenarios indicated that setting up a relatively larger reference population and adopting a less-frequent DMI sampling scenario (e.g., SCN3) is promising. When the same reference population size was considered, the genomic prediction accuracy of SCN3 was only 5.0 to 7.0 percentage points lower than that for the most expensive DMI recording strategy (SCN1). We concluded that DMI recording strategies that are sparse in terms of records per cow but with slightly more cows recorded per sire are advantageous both in genomic selection and in traditional progeny testing schemes when accuracy, logistics, and cost implications are considered.

Key words: dairy cattle, feed efficiency, dry matter intake, reliability, genetic parameter

\section{INTRODUCTION}

The efficiency and accuracy of selection for feed utilization efficiency in livestock depends on the availability of large numbers of animals with high-quality feed intake records. As a consequence, there is now an increasing demand for a large database with feed intake as a phenotype for dairy and beef cattle breeding programs (Chizzotti et al., 2015), research on feed intake 
as a proxy for enteric methane production (Negussie et al., 2017), and precision livestock farming (Chizzotti et al., 2015). These all have motivated the generation and regular monitoring of feed intake on individual animals and on a large scale. Furthermore, feed costs are the largest single expense in dairy herds, and the proper management of these costs contributes to a dairy's profitability. There is therefore now a great interest in expanding dairy breeding goals to include traits related to feed utilization efficiency as a more logical and sustainable approach.

However, including feed efficiency $(\mathbf{F E})$ as a selection criterion is constrained by the fact that many definitions of FE traits such as residual feed intake (RFI; Koch et al., 1963), gross FE (Korver, 1988; Van Arendonk et al., 1991; Spurlock et al., 2012), and feed saved (Pryce et al., 2015) require in their calculations recordings on the DMI of cows. Such measurements on individual animals and particularly on a large scale in commercial farms are costly and logistically demanding. As a result, recordings of feed intake and recording strategies in commercial dairy herds are practically nonexistent. Because low-cost and accurate on-farm recording of DMI in dairy cows is a requisite for accurate estimation of EBV for FE traits, assessing how different scenarios best provide accurate EBV for the investment in logistics and running cost is essential.

Currently, DMI observations in dairy cows are resourced mainly from on-station experiments and research farms. The DMI records from such sources are very limited for a large-scale and accurate genetic or genomic analysis. To get a reliable estimate of genetic parameters and genomic predictions, sizable and quality data should be resourced not only from research farms but also from commercial dairy herds. Collecting individual animal DMI records in large amounts and from commercial herds requires low-cost on-farm DMI recording equipment and strategies that offer a sizable throughput without adverse effect on the accuracy of EBV for DMI and FE traits.

On-farm recording of feed intake from individual cows was practiced in tiestall barns with manual weighing out and weighing back of rations comprising separate feed items such as silage, sugar beets, hay, and concentrates (e.g., Mason et al., 1957). The process was laborious and over the years has been replaced by automated feeding stations with electronic scales and computerized recording (e.g., Bach et al., 2004; Chizzotti et al., 2015). Such complete schemes are characteristics of most traditional on-station daily recording systems. They are more comprehensive and accurate than any of the interval-based (i.e., less than complete) recording schemes. However, these systems are very expensive to establish and almost impossible to move between farms, so they are not available to provide the required data. Alternative developments based on markers have been tried and reported (Ahvenjärvi et al., 2018). More recently, inexpensive cameras and image analyses have been suggested (Lassen et al., 2018), but they are in need of further developments, testing, and validation. In any case, planning DMI recording using anything less than complete schemes requires insights into the consequences for the obtained accuracies.

Generally, in an on-farm DM recording, the intensity of recording on each cow along with the number of animals to be sampled and the stage of lactation at which records are collected will have a significant effect on cost, logistical demands, and, particularly, on the accuracy of EBV for DMI and FE traits. Previous studies on the genetic analysis of feed intake fitting test-day random regression models (RRM) have reported genetic associations ranging from -0.5 to 0.98 (Veerkamp and Thompson, 1999; Buttchereit et al., 2011; Manzanilla-Pech et al., 2014b; Li et al., 2018) between different DIM. Most of the results reported provided estimates of genetic associations between DMI during specific days, specific intervals, or specific periods (e.g., early-, mid-, and late-lactation periods; Manzanilla-Pech et al., 2014a; Tetens et al., 2014; Li et al., 2016). In general, DMI in early lactation is in low genetic correlation with that in mid to late lactation, whereas DMI within mid to late lactation is highly correlated (Manzanilla-Pech et al., 2014a,b). Based on this and other related studies, various tests have been made to find out when would be the best time to record DMI in dairy cows. Manzanilla-Pech et al. (2014a) estimated the accuracies of recording DMI continuously during lactation starting at 5, 10, and 15 wk. They reported that accuracies were highest when the length of the recording period was longest. In view of practical onfarm recording scenarios, however, a continuous DMI recording strategy may be either extremely demanding logistically or prohibitively expensive for routine implementation on-farm. Even when such constraints are addressed, fixing DMI recording on-farm to one longer specific period or interval during lactation would result in either small contemporary group sizes or in contemporary groups in which some of the cows have consumed feed of different nutritional composition or quality. All of these circumstances have the potential to compromise data analysis and affect the accuracy of EBV. Therefore, a better understanding of the effects of different DMI recording strategies on the reliability of EBV for DMI and FE traits is essential for establishing an optimal on-farm DMI recording design. Therefore, the main objectives of this study were (1) to estimate genetic parameters for DMI and FE traits in Nordic Red cattle fitting RRM and (2) to use these estimates 
in a simulation study to assess the accuracy of EBV for DMI and FE traits under different on-farm DMI recording scenarios. In addition, in genomic selection, results of the simulation study were used to assess sizes of the required reference populations and the associated genomic prediction accuracies for different on-farm DMI recording scenarios.

\section{MATERIALS AND METHODS}

\section{Data}

The data used for the estimation of variance components and associated genetic parameters were recorded at the Luke research dairy farm in Jokioinen, Finland, which maintains the Nordic Red Dairy Cattle (RDC) breeding nucleus cows from Finland and Sweden. The care and use of animals in the herd have been described in Mäntysaari and Mäntysaari (2015). The data were from feed intake records compiled since 2009, when automated daily feed intake, BW, and milk production data collection systems have been used with the main purpose of studying the genetic variations in the components of FE traits.

The data used for the estimation of variance components included 38,421 daily DMI observations from 227 primiparous Nordic RDC cows recorded from wk 2 to 40 of lactation. Cows were due to calf in the autumn seasons to ensure that cows were at the end of lactation or in their dry period during the following summer pasture season. During the pasture months, DMI was not recorded, and thus data for animals that were still lactating during this period are lacking. The data were edited in such a way that records from the first week of lactation were discarded, mainly due to the observed high variability in studied traits at the beginning of lactation and also due to the effects such records may have on the estimates of genetic parameters. All cows were weighed using an automated scale twice daily when leaving the milking parlor after milking. To calculate BW and BW changes for each animal, measured weights were modeled by RRM fitting a second-order polynomial term and a Wilmink function (Wilmink, 1987; Mäntysaari and Mäntysaari, 2015). The daily BW of the cows were then predicted from the individual curves as described in Mäntysaari and Mäntysaari (2015) and BW change (weight gain or loss was calculated as a difference between any consecutive daily weights).

\section{Traits}

The final data included daily records on ECM $(\mathrm{kg}$; Sjaunja et al., 1991), DMI (kg), RFI (kg/d), and energy
Table 1. Description of DMI, residual feed intake (RFI), and energy conversion efficiency (ECE) traits

\begin{tabular}{lcrc}
\hline Trait & $\begin{array}{c}\text { No. of } \\
\text { observations }\end{array}$ & Mean & SD \\
\hline DMI (kg/d) & 38,421 & 19.90 & 2.90 \\
RFI (kg of DM/d) & 38,354 & 0.03 & 1.46 \\
ECE (kg/MJ of ME) & 38,421 & 1.48 & 0.27 \\
\hline
\end{tabular}

conversion efficiency (ECE; $\mathrm{kg} / \mathrm{MJ}$ of $\mathrm{ME}$ ), which was calculated as ECM $(\mathrm{kg})$ per unit of ME intake. The RFI was calculated as residuals from a regression of the actual DMI on ECM, BW, and BW change. The pedigree file had 2,409 animals pruned to 5 generations. The final data used for the estimation of variance components included 38,421 records. The overall means of daily DMI, RFI, and ECE observations were $19.9 \mathrm{~kg} / \mathrm{d}$, $0.03 \mathrm{~kg} / \mathrm{d}$, and $1.48 \mathrm{~kg} / \mathrm{MJ}$ of ME, respectively. Table 1 presents details of the data used in this study.

\section{Model}

Variance components and the corresponding genetic parameters for the daily DMI, RFI, and ECE were estimated using RRM. The RRM fitted orthogonal Legendre polynomials as a function of DIM (van der Werf et al., 1998) to model the fixed regression curves as well as the permanent environmental and additive genetic variations across lactation for DMI, RFI, and ECE traits. Each trait was analyzed using a univariate RRM that can be described as

$$
\begin{aligned}
& y_{i j k l m}=\operatorname{age}_{i}+\text { cys }_{j}+\sum_{r=0}^{4} D_{l r} \boldsymbol{\phi}_{\pi}(d)_{r}+c_{k}+\sum_{r=0}^{2} p_{m r} \phi_{\alpha}(d)_{r} \\
& +\sum_{r=0}^{2} a_{m r} \phi_{\alpha}(d)_{r}+\varepsilon_{i j k l m},
\end{aligned}
$$

where $y_{i j k l m n}$ is a daily observation of cow $m$ recorded at age $i$ (age at calving in months) within calving year $\times$ season (cys) $j$ (where a calving year was divided into 4 seasons: November to February, March to April, May to July, and August to October) and on recording date $k ; D_{l r}$ is a fixed regression coefficient on DIM $=d$ with the $r$ th covariable $\phi_{\pi}(d)_{r}$ of a fourth-order Legendre polynomial plus Wilmink term function to describe the shape of the trajectory during lactation (Negussie et al., 2006), where functions were nested within calving year $\times$ calving season classes $l ; c_{k}$ is the fixed effect of recording date; $p_{m r}$ is the $r$ th random regression coefficient for the permanent environmental effect of cow $m ; a_{m r}$ is the $r$ th random regression coefficient for the additive genetic effect of cow $m$, where $\phi_{\alpha}(d)_{r}$ is the $r$ th 
covariable of a second-order Legendre polynomial; and $\varepsilon_{i j k l m}$ is the random residual.

The covariables in $\phi_{\alpha}(d)$ were a subset of

$$
\phi_{\pi}(d)=\left[\begin{array}{llllll}
c_{0} & c_{1} & c_{2} & c_{3} & c_{4} & \exp (w d)
\end{array}\right]^{\prime}
$$

where $c_{0}, c_{1}, c_{2}, c_{3}$, and $c_{4}$ are coefficients of the fourthorder orthogonal Legendre polynomial at DIM $d$, and $w$ is a coefficient of the exponential term of the Wilmink function (Wilmink, 1987). The coefficient of the exponential term $w$ that fitted the current data for modeling the fixed regression curves was estimated to be -0.05 .

The covariance structure for random additive genetic animal effects a, permanent environmental effects $\mathbf{p}$, and residual effects e was defined as

$$
\operatorname{Var}\left[\begin{array}{l}
\mathbf{a} \\
\mathbf{p} \\
\mathbf{e}
\end{array}\right]=\left[\begin{array}{ccc}
\mathbf{G} \otimes \mathbf{A} & 0 & 0 \\
0 & \mathbf{P} \otimes \mathbf{I} & 0 \\
0 & 0 & \mathbf{I} \sigma_{\varepsilon}^{2}
\end{array}\right],
$$

where $\mathbf{G}$ and $\mathbf{P}$ are covariance matrices of the random regression coefficients for animal additive genetic effects $\mathbf{a}_{m}$ and cow permanent environmental effects $\mathbf{p}_{m}$, $\mathbf{R}=\mathbf{I} \sigma_{\varepsilon}^{2}$ is the variance of the random residual, $\mathbf{A}$ is the matrix of additive genetic relationships among animals, $\otimes$ is the Kronecker product, and $\mathbf{I}$ is an identity matrix. The multivariate mixed model package DMU was used for the estimation of variance components using the AI-REML procedure (Madsen and Jensen, 2013). Estimated covariance components of the random regression coefficients for animal additive genetic and cow permanent environmental effects were then used to derive daily heritabilities and genetic and phenotypic associations.

\section{Calculation of Genetic Parameters}

Daily animal genetic variance $\sigma_{a}^{2}$ at DIM $d_{i}$ was calculated as

$$
\sigma_{a}^{2}\left(d_{i}\right)=\phi_{\alpha}^{\prime}\left(d_{i}\right) \mathbf{G} \phi_{\alpha}\left(d_{i}\right)
$$

where $\mathbf{G}$ is the covariance matrix of the random animal genetic regression coefficients and $\phi_{\alpha}$ is set of secondorder Legendre covariables. Heritability $\hat{h}^{2}$ at DIM $d_{i}$ along lactation was calculated as

$$
\hat{h}_{d i}^{2}=\hat{\sigma}_{a}^{2}\left(d_{i}\right) /\left[\hat{\sigma}_{e}^{2}\left(d_{i}\right)+\hat{\sigma}_{p}^{2}\left(d_{i}\right)+\hat{\sigma}_{a}^{2}\left(d_{i}\right)\right],
$$

where $\hat{\sigma}_{e}^{2}$ is the random residual variance and $\hat{\sigma}_{p}^{2}$ is the variance of permanent environmental effects given as $\phi_{\alpha}^{\prime}\left(d_{i}\right) \mathbf{P} \phi_{\alpha}\left(d_{i}\right)$, where $\boldsymbol{\phi}_{\alpha}$ is set of second-order Legendre covariables and $\mathbf{P}$ is covariance matrix of the permanent environmental regression coefficients. Genetic correlations between 2 DIM during lactation $d_{i}$ and $d_{j}$ were calculated as

$$
\hat{\mathrm{r}}_{g}\left(d_{i j}\right)=\frac{\phi_{\alpha}^{\prime}\left(d_{i}\right) \mathbf{G} \boldsymbol{\phi}_{\alpha}\left(d_{j}\right)}{\sqrt{\sigma_{a}^{2}\left(d_{i}\right) \times \sigma_{a}^{2}\left(d_{j}\right)}},
$$

where $\hat{\mathrm{r}}_{g}$ is the genetic correlation between DMI at 2 DIM during lactation $d_{i}$ and $d_{j}$; $\mathbf{G}$ is the covariance matrix of the random animal genetic regression coefficients; $\sigma_{a}^{2}\left(d_{i}\right)$ and $\sigma_{a}^{2}\left(d_{j}\right)$ are animal genetic variances at DIM $d_{i}$ and $d_{j}$, respectively; and $\phi_{\alpha}$ is the set of secondorder Legendre covariables.

\section{Simulation of Different On-Farm DMI Recording Scenarios}

Within lactation, genetic correlations for DMI, ECE, and RFI among different DIM deviate significantly from unity. In particular, the beginning of lactation has lower correlations with DMI at the other stages of lactation. A very sparse DMI recording practice will therefore yield a significantly lower accuracy than is expected from simple index calculations. To address this, different DMI recording scenarios (SCN) were simulated to assess how the accuracy of breeding values is affected by varying the interval and intensity of onfarm DMI recording. Five on-farm DMI recording scenarios were evaluated: DMI recorded once every week (SCN1), DMI recorded once every month (SCN2), DMI recorded once every 2 mo (SCN3), DMI recorded once every 3 mo (SCN4), and DMI recorded once every 4 mo (SCN5), as shown in Table 2.

Simulation of Phenotypes and True Breeding Values. To emulate realistic on-farm DMI recording conditions, the simulation was based on a real data and pedigree structure recorded at the Danish research farm in Foulum, Denmark. The data from 789 Holstein cows contained 36,037 weekly observations and had an associated pedigree of 24,997 animals. In the first step, for each animal, true RRM breeding value solutions were simulated and weekly observations were replaced by simulated daily observations for each of the traits under study. In the following step, data subsamples for the different SCN were drawn from the full simulated data per the definition of each scenario. Details of the sampling scenarios, including the frequency of sampling and the final number of observations available for each scenario, are given in Table 2 . 
Table 2. Description of data sets simulated for the different scenarios (SCN) of DMI, residual feed intake (RFI), and energy conversion efficiency (ECE) traits by number of observation available per cow and total observations

\begin{tabular}{llcc}
\hline Scenario & $\begin{array}{l}\text { DMI recording } \\
\text { interval }\end{array}$ & $\begin{array}{c}\text { No. of } \\
\text { observations/cow }\end{array}$ & $\begin{array}{c}\text { Total no. } \\
\text { of observations }\end{array}$ \\
\hline SCN1 & Once weekly & 34.7 & 25,636 \\
SCN2 & Once monthly & 9.5 & 6,986 \\
SCN3 & Once every 2 mo & 4.4 & 3,239 \\
SCN4 & Once every 3 mo & 3.1 & 2,299 \\
SCN5 & Once every 4 mo & 2.3 & 1,691 \\
\hline
\end{tabular}

${ }^{1}$ Each scenario has 5 replicates of simulated data set for each of DMI, RFI, and ECE phenotypes.

During simulation, the variance components estimated from the daily observations of Nordic Red cattle were used as an input. The same RRM, as used for the variance component estimation, was applied for simulating true breeding value regression coefficients and daily DMI observations. Correlated random effect regression coefficients in the model were generated from a normal distribution applying Cholesky decomposition of the estimated (co)variance matrices. Each animal's true breeding value regression coefficients were generated as the average of the parents' true breeding value regression coefficients plus generated Mendelian sampling deviation regression coefficients. Values of fixed effects do not affect the distribution of random variables (García-Cortés et al., 1995) and thus were simulated with values of zero. Phantom parent group effects were also set to zero. Daily observations were then formed by summing for each record the corresponding fixed and random effects and adding a random error term, which was simulated from a normal distribution, and applying the estimated residual variance. Finally, 5 independent data replicates were simulated for each trait. The data were simulated using MiX99 software (Strandén and Lidauer, 1999).

Accuracy of $\boldsymbol{E B V}$. Breeding values were estimated for all traits and for each of their 5 scenarios and 5 replicates (i.e., yielding 125 sets of breeding values). The model used for the estimation of breeding values was the same as the model used for the estimation of variance components and for generating the simulated data sets. Mixed-model equations were solved using MiX99 software (Strandén and Lidauer, 1999). For each trait, the random regression coefficients of the breeding value solutions were compiled to calculate the sum of EBV over d 8 to 280 to get EBV on a lactation basis $\left(\mathrm{EBV}_{8-280 \mathrm{~d}}\right)$ as follows:

$$
\mathrm{EBV}_{i j m}=\sum_{d=8}^{280} \phi(d) \hat{a}_{m}
$$

Similarly, the simulated regression coefficients for the true breeding values were used to compile true breeding values on a lactation basis $\left(\mathrm{TBV}_{8-280 \mathrm{~d}}\right)$ as follows:

$$
\mathrm{TBV}_{i j m}=\sum_{d=8}^{280} \phi(d) a_{m}
$$

where $\mathrm{TBV}_{i j m}$ and $\mathrm{EBV}_{i j m}$ are true and $\mathrm{EBV}$, respectively, for scenario $i$ replicate $j$ and animal $m ; \phi(d)$ is the set of second-order Legendre covariables for DIM $d ; \hat{a}_{m}$ is the regression coefficient for the EBV for animal $m$; and $a_{m}$ is the regression coefficient for the true breeding values of animal $m$. Accuracies were calculated within each trait, for each scenario $i$ and each replicate $j$, as the correlation between the true $\left(\mathrm{TBV}_{i j m}\right)$ and estimated $\left(\mathrm{EBV}_{i j m}\right)$ breeding values, and the obtained accuracies from the 5 replicates were averaged for each scenario. Finally, reliabilities (squared accuracies) were calculated for cows that were born after 2005 and had at least $1 \mathrm{DMI}$ observation to evaluate changes in the reliability of EBV associated with the changes in the sparsity of DMI recording in the different scenarios. In addition, the obtained reliabilities for DMI were used in selection index calculations to demonstrate how the different recording schemes affect the reliabilities of sire $\mathrm{EBV}$, the number of daughters, and the number of DMI observations to be recorded on-farm. Following a progeny testing scheme, the necessary number of daughters to be recorded to achieve a desired reliability for a sire EBV can be approximated by

$$
n=\frac{b}{(1-b)} \frac{\left(4-r_{T I}^{2}\right)}{r_{T I}^{2}}
$$

where $n$ is the number of daughters needed, $b$ is the desired reliability of the sire EBV, and $r_{T I}^{2}$ is the squared correlation between estimated and true breeding values of the daughters for a given sampling scenario.

Furthermore, based on the different on-farm DMI recording strategies tested in this study, the associated genomic prediction accuracy in the selection candidates was calculated. The accuracies were calculated following Erbe et al. (2011) and were based on the equation derived by Daetwyler et al. (2008, 2010). For this, the heritability of DMI, reference populations ranging from 
0 to 20,000 and empirically determined and widely used estimates for the number of independent chromosome segments for Holstein cattle ( $\mathrm{Me} \sim 1,000$; Erbe et al., 2011) were used as an input:

$$
r_{g g G} \approx \sqrt{\frac{N_{p} h^{2}}{N_{p} h^{2}+M_{e}}}
$$

and

$$
M_{e}=2 N_{e} L / \log \left(4 N_{e} L\right),
$$

where $r_{g g G}$ is the approximated accuracy of genomic predication for selection candidates; $N_{p}$ is the size of the reference population; $h^{2}$ is the heritability, which was assumed to be equal to $r_{T I}^{2} ; M_{e}$ is the number of independent chromosome segments; $N_{e}$ is the effective population size; and $L$ is the genome length in morgans.

\section{RESULTS}

\section{Daily Averages of DMI, RFI, and ECE Across Lactation Stages}

The daily means of DMI, RFI, and ECE along with the number of observations are plotted in Figure 1a-c. The mean daily DMI at the beginning of lactation was lower and started to increase gradually until DIM 75 , where it started to level off until DIM 250 (Figure 1a). For RFI, the daily means were negative at the beginning of lactation (DIM 8 to 30) and started to increase gradually at DIM 50 until DIM 100 and remained positive afterward. After mid lactation, however, it followed a slightly downward trend toward zero before it started to increase again at the end of lactation (Figure 1b). Conversely, daily means for ECE were higher at the beginning of lactation, and the trend afterward was one of gradual decline followed by leveling off toward the end of the lactation period (Figure 1c). The dotted black lines in Figure 1a-c show the number of observations available for the analysis of each of the traits during the different stages of lactation. Although the number of records available for DMI varied during the whole lactation period, the largest part was recorded during the early- to mid-lactation period until DIM 50. After DIM 50, however, the trend was one of declining as the stages of lactation progressed. The overall trend of number of observations available for the RFI and ECE traits was similar, mainly because these traits were derived in part as a function of DMI observations and are expected to follow a similar pattern (Figure 1a-c).

\section{Genetic Parameters}

Estimates of the daily heritability $\left(\mathrm{h}^{2}\right)$ for DMI and the $2 \mathrm{FE}$ traits RFI and ECE are shown in Figure 2. The estimated lactation-wise or whole-lactation heritability for DMI over DIM 8 to 280 was 0.33 . During lactation, the daily heritability of DMI ranged from 0.18 to 0.40 . The estimate was slightly higher (0.35) at the beginning of lactation and later declined to 0.18 in mid lactation. After mid lactation, the estimates of heritability started to increase gradually toward late lactation. The trends for daily heritability estimates of the other 2 traits (RFI and ECE) followed similar patterns. The estimated lactation-wise heritability for RFI was 0.12 . The daily heritability for RFI was higher during early lactation than in mid lactation. Its heritability declined from 0.33 at the beginning of lactation to about 0.07 by DIM 75 , and afterward it started to increase gradually starting at DIM 140 . For ECE, the estimated lactation-wise heritability was 0.32 . The trend for daily heritability of ECE was similar to that of DMI, but it was much higher at the beginning of lactation $(\sim 0.40)$ than the estimates for DMI and RFI. The estimate, however, declined markedly soon after early lactation to 0.10 at DIM 145 in mid lactation and continued its downward trend until DIM 210, where it started to gradually increase again.

In this study, genetic correlations between DMI at different DIM ranged from -0.5 to 0.98 . The genetic correlations at selected DIM 15, 90, 150, and 280 with all the other days in lactation are shown in Figure 3. The figure shows that genetic correlations of DMI at DIM 15 with DMI at all other DIM were close to unity in early lactation but declined quickly to 0.5 at DIM 100 and were negative after DIM 160 and onward. The genetic correlations of DMI at DIM 90 with DMI at all other DIM were 0.6 in early lactation and increased gradually to 0.95 by DIM 100 and declined to zero by DIM 230. On the other hand, genetic correlations of DMI at DIM 150 in mid lactation with DMI at all other DIM were lower at the beginning of lactation and peaked at DIM 150 before they started to decline to 0.3 at DIM 280. Genetic correlations of DMI at DIM 280 were negative with early lactation but were largely high and positive with DMI at mid- and late-lactation stages.

\section{Reliability of EBV}

The squared accuracies (reliabilities) of cow EBV for the different DMI sampling scenarios are given by traits in Table 3. The results show that, in general, the accuracy of EBV declined with the increase in 
(a)

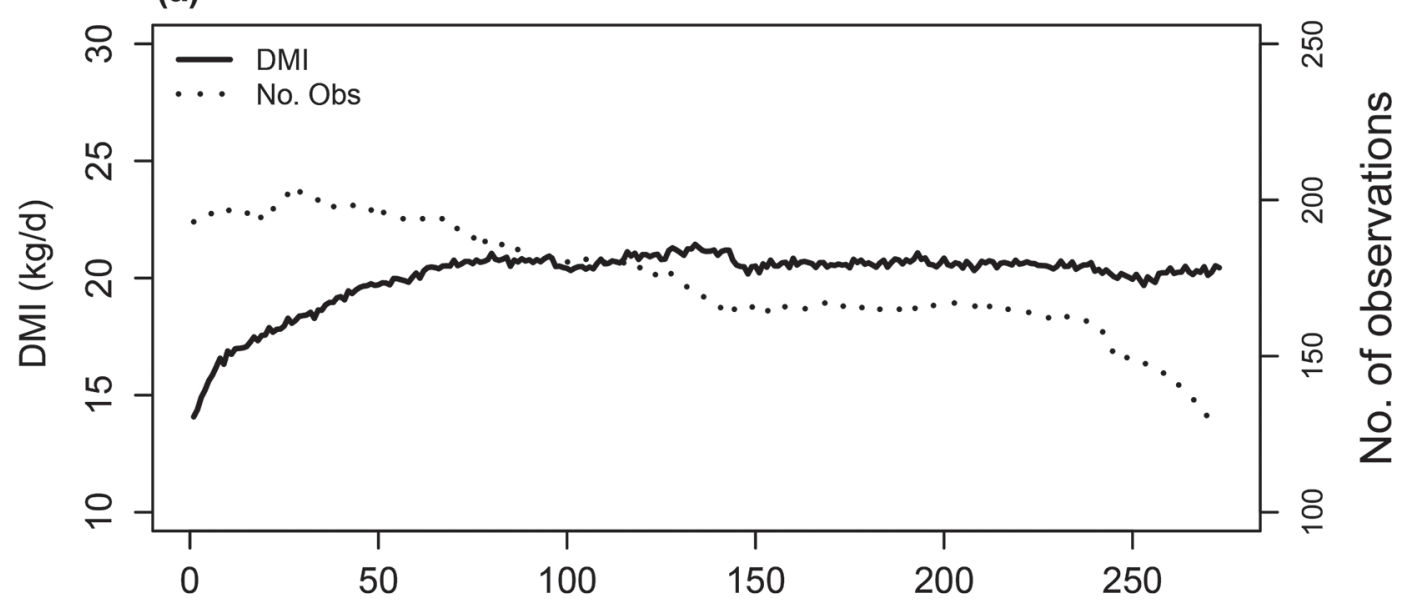

(b)

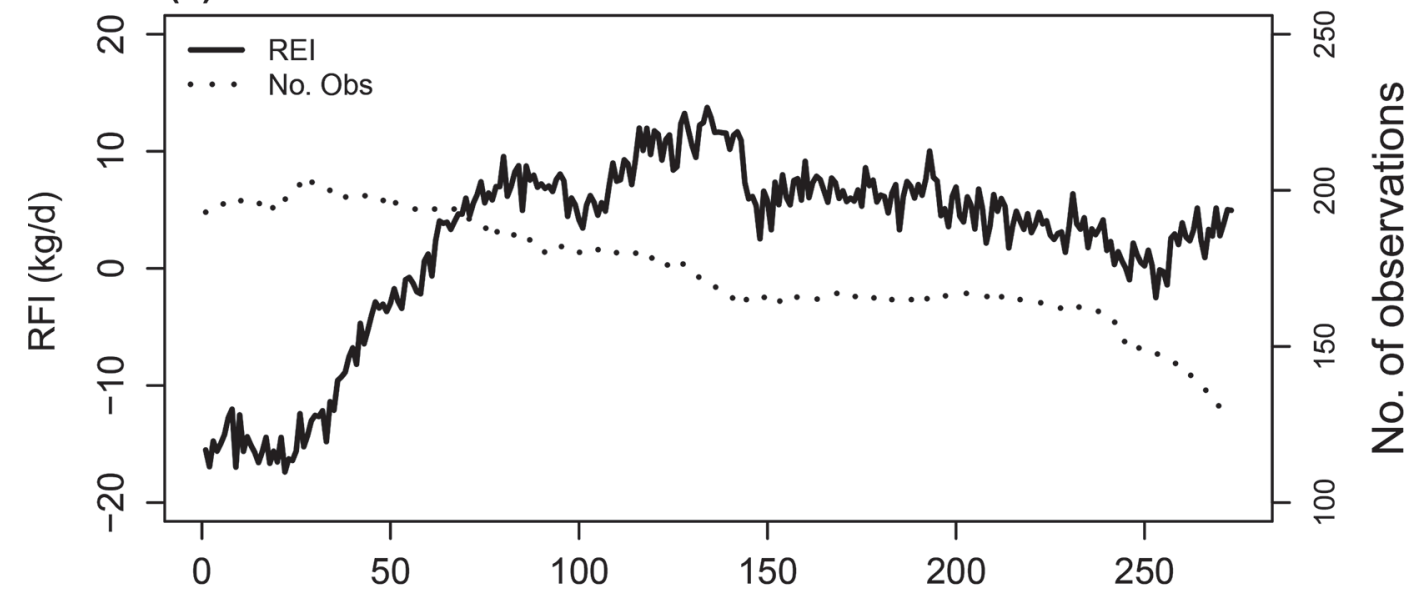

(c)

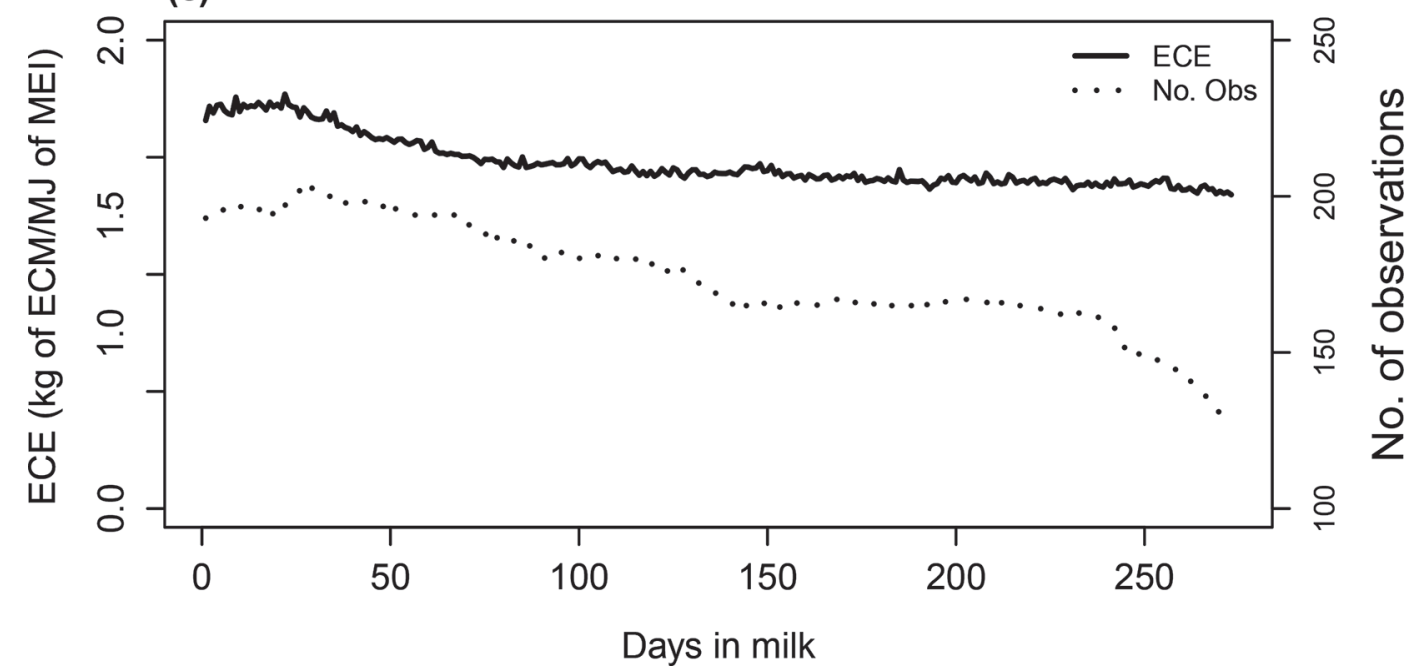

Figure 1. Daily means (solid black lines) and corresponding number of observations (Obs; dotted black lines) for (a) DMI, (b) residual feed intake (RFI), and (c) energy conversion efficiency (ECE) traits given by DIM for primiparous Nordic Red cows at the Jokioinen research dairy farm in Finland. MEI = ME intake. 
sampling interval or frequency. For instance, for DMI, the reliability of cow EBV was 0.32 when DMI was collected once per week (SCN1) and declined to 0.18 when DMI was recoded once every 4 mo (SCN5). For RFI, the reliability of cow EBV was 0.25 when DMI was sampled every week and declined to 0.09 when DMI was sampled once every 2 mo (SCN3). For ECE, reliability of EBV was 0.40 when DMI was recorded once weekly and declined to 0.31 when records were taken once every 2 mo (SCN3).

Considering progeny testing under the 5 DMI recording schemes, the number of daughters and DMI observations to be recorded for sire EBV reliabilities of 0.4, 0.6, and 0.8 are shown in Table 4 . With once per week DMI sampling (SCN1), a sire EBV reliability of 0.4 can be achieved with recording about 8 daughters per sire, but the number of total observations required per sire was 277 . To achieve the same reliability of 0.4 with sampling once every 4 mo (SCN5) the number of daughters required per sire has to be doubled, but the number of required DMI observations per sire was about 32. Similarly, for SCN1 and a sire reliability of 0.8 , the approximate number of daughters to be recorded and the associated number of observations needed per sire were 46 and 1,596, respectively. To achieve this same level of sire reliability with SCN5, the required number of daughters to be recorded per sire has to be doubled to 85 but the number of DMI observations to be collected per sire is reduced markedly to 196 .
Assuming that genomic selection was considered, we also calculated the expected reliabilities for the different scenarios. Our results showed that with more-frequent DMI recording scenarios (SCN1 and SCN2), a relatively small reference population gave a higher accuracy than the less-frequent DMI recording scenarios (Figure 4). For instance, when implementing SCN1, a genomic prediction accuracy of 0.6 could be realized with a reference population of about 2,000 animals, whereas when implementing a less-frequent DMI recording strategy (e.g., SCN4 or SCN5), a reference population of about 4,000 animals was required to attain a similar genomic prediction accuracy of 0.6. Likewise, compared with SCN2, SCN5 required a reference population twice the size of the reference population required for SCN2 to attain a genomic prediction accuracy of 0.6. On the other hand, of all the scenarios tested the difference in genomic prediction accuracy and size of the reference population between the more-frequent scenario SCN1 and that of SCN3 was somewhat negligible despite the large difference in the interval and frequency of DMI recording.

\section{DISCUSSION}

\section{Estimates of Genetic Parameters}

The health and productive output of dairy cows is closely related to individual cow feed intake. In dairy

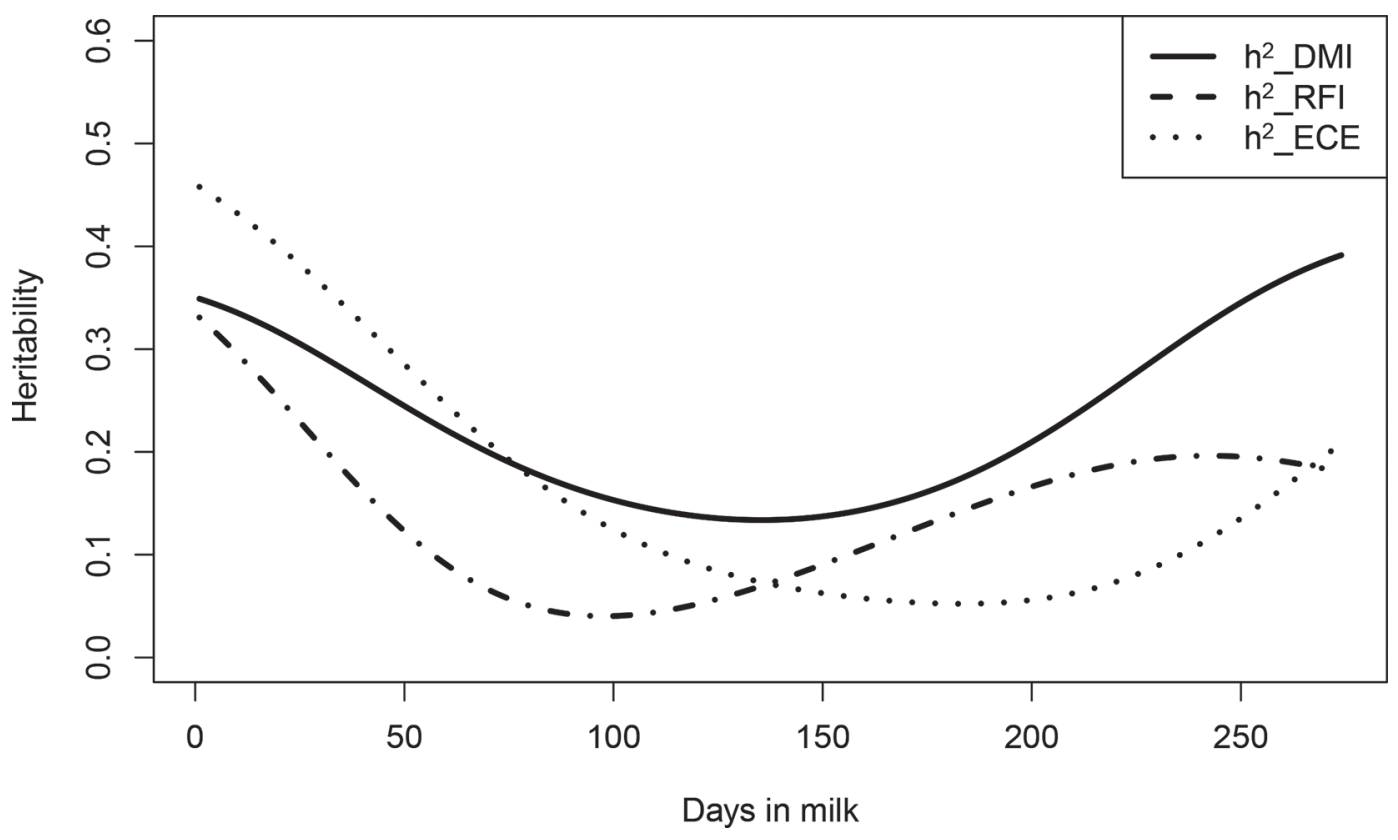

Figure 2. Estimates of daily heritability for DMI, residual feed intake (RFI), and energy conversion efficiency (ECE) during lactation in Nordic Red cows. 
Table 3. Reliability of EBV for DMI, residual feed intake (RFI), and energy conversion efficiency (ECE) for cows with observations and born in 2005 onward $^{1}$

\begin{tabular}{lccc}
\hline & \multicolumn{3}{c}{$\left(\mathrm{r}_{\mathrm{TBV}, \mathrm{EBV}}\right)^{2}$} \\
\cline { 2 - 4 } $\begin{array}{l}\text { DMI recording } \\
\text { scenario }\end{array}$ & DMI & RFI & ECE \\
\hline SCN1 & 0.32 & 0.25 & 0.40 \\
SCN2 & 0.28 & 0.13 & 0.36 \\
SCN3 & 0.24 & 0.09 & 0.31 \\
SCN4 & 0.23 & 0.06 & 0.26 \\
SCN5 & 0.18 & 0.05 & 0.21 \\
\hline
\end{tabular}

${ }^{1} \mathrm{r}=$ correlation; $\mathrm{TBV}=$ true breeding value.

${ }^{2} \mathrm{SCN} 1$ = recording once every week; SCN2 = recording once every month; SCN3 = recording once every $2 \mathrm{mo}$; $\mathrm{SCN} 4=$ recording once every $3 \mathrm{mo}$; SCN5 = recording once every 4 mo.

cattle, an increase in milk yield is associated with higher DMI. The link between DMI and production is easy to appreciate, and from a production standpoint it is one of the critical components of maximizing milk production and financial efficiency. Dry matter intake in dairy cows is affected by a multitude of factors, and one of them is genetics. Several studies have reported that genetic variation for DMI exists (Veerkamp and Thompson, 1999; Coffey et al., 2004; Berry et al., 2007; Vallimont et al., 2010; Manzanilla-Pech et al., 2014b; Li et al., 2017). It varies with breeds or populations, lactation stages, data, and estimation models, but estimates of genetic variations for DMI from data covering the most critical stages of lactation are still scant in the literature.
Table 4. Reliability of EBV for DMI and approximate number of daughters and the corresponding number of observations required for varying levels of reliability of sire $\mathrm{EBV}(0.4,0.6$, and 0.8$)$ based on the 5 DMI recording scenarios ${ }^{1}$

\begin{tabular}{lrrr}
\hline & \multicolumn{3}{c}{ Reliability } \\
\cline { 2 - 4 } Item & 0.4 & 0.6 & 0.8 \\
\hline No. of daughters/sire & 8 & 17 & 46 \\
SCN1 & 9 & 19 & 53 \\
SCN2 & 10 & 24 & 63 \\
SCN3 & 11 & 25 & 66 \\
SCN4 & 14 & 32 & 85 \\
SCN5 & & & \\
No. of DMI observations/sire & 277 & 590 & 1,596 \\
SCN1 & 86 & 181 & 504 \\
SCN2 & 44 & 106 & 277 \\
SCN3 & 34 & 78 & 205 \\
SCN4 & 32 & 74 & 196 \\
SCN5 & & \\
\hline
\end{tabular}

${ }^{1} \mathrm{SCN} 1=$ recording once every week; SCN2 $=$ recording once every month; SCN3 = recording once every 2 mo; SCN4 = recording once every 3 mo; SCN5 = recording once every 4 mo.

For the purposes of this study, it was necessary to obtain RRM variance components for daily DMI, RFI, and ECE on data from Nordic RDC that covered a period of 8 to 280 DIM. Lactation-wise heritability estimates were then derived from the estimated variance components. The derived lactation-wise heritability for DMI during lactation (8 to 280 DIM) was 0.33, which was slightly lower than the estimate reported by Manzanilla-Pech et al. (2014b). Based on data covering the first $324 \mathrm{~d}$ of lactation, they reported a lactation-

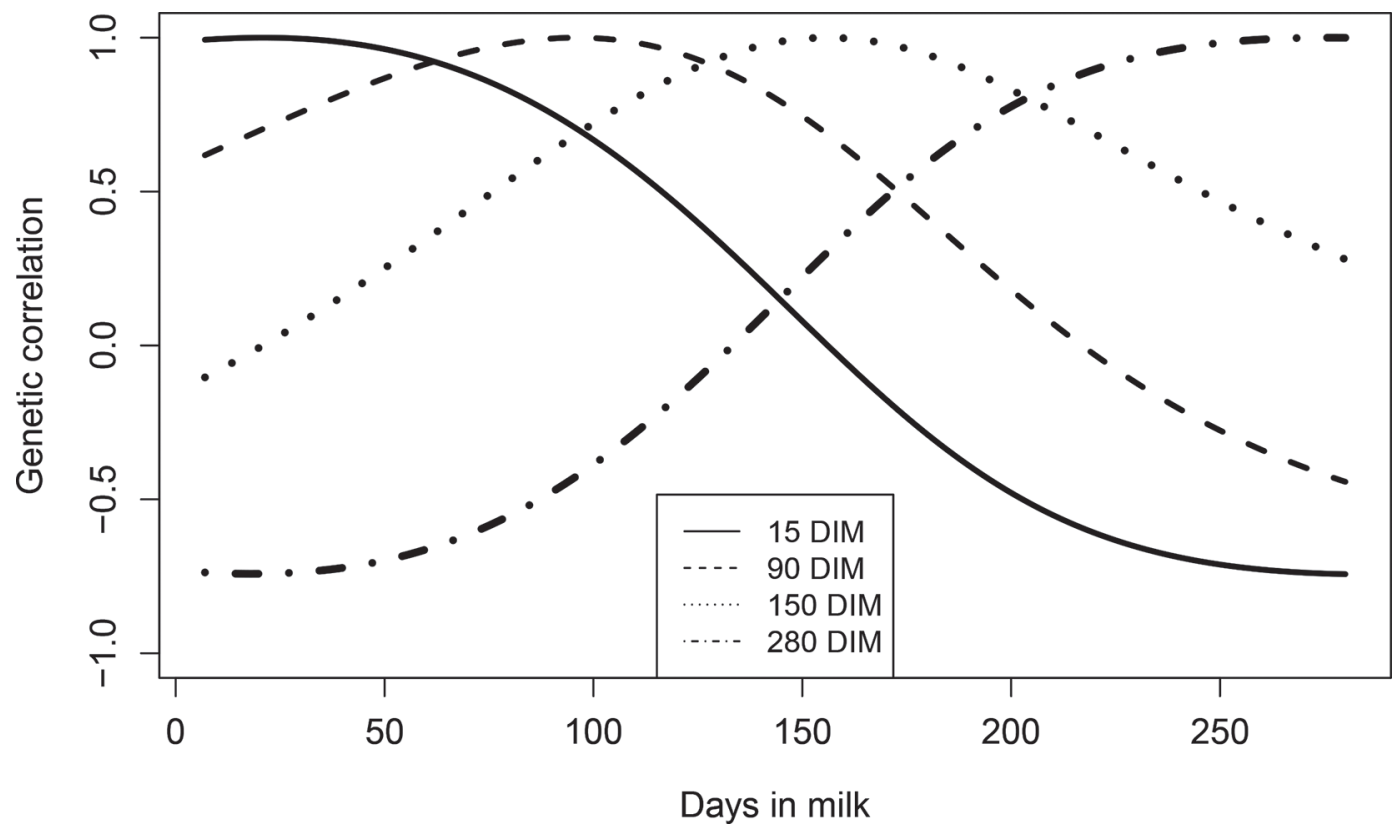

Figure 3. Genetic correlations between DMI at 15, 90, 150, and 280 DIM and DMI at all other DIM in Nordic Red cows. 
wise heritability of 0.46 for Dutch Holsteins. On the other hand, in the current study, the daily heritability for DMI ranged from 0.18 to 0.40 . This is close to the range of 0.20 to 0.40 estimated for the Dutch Holsteins and the range of 0.18 to 0.38 estimated by Liinamo et al. (2015), who used weekly average DMI data covering 2 to 30 wk of lactation.

The lactation-wise heritabilities of RFI and ECE were 0.12 and 0.32 , respectively, and the daily heritabilities of these 2 traits ranged from 0.07 to 0.14 and 0.12 to 0.43 , respectively. Using weekly average data, Mehtiö et al. (2018) reported a heritability of 0.33 for residual energy intake (REI), which is slightly higher than the estimates found in earlier reports (Liinamo et al., 2015; Tempelman et al., 2015; Hurley et al., 2017). The wide range of estimated daily heritabilities for both RFI and ECE traits confirmed that these traits have different genetic bases during the different stages of lactation. Recent reports by Li et al. (2017), Liinamo et al. (2015), and Tempelman et al. (2015) confirmed that heritability estimates of RFI or REI vary during lactation and ranged from 0.06 to 0.24. Similarly, Hurley et al. (2017) reported heritability of 0.06 (at DIM 50 ) and 0.28 (at DIM 250) for ECE, whereas Liinamo et al. (2015) reported that heritability estimates for
ECE were lowest between 11 and 14 wk of lactation and increased toward late lactation, ranging from 0.01 to 0.40 during lactation.

Identifying an optimal strategy for an on-farm DMI recording was one of the main objectives of this study. For this, a better understanding of the genetic associations between DMI at different stages of lactation is essential. In Figure 3, genetic correlations between DMI at DIM 15, 90, 150, and 280 and all the other days are presented. The results show that except for adjacent DIM, correlations between different DIM were less than unity and ranged from -0.5 to 0.9 . This is in line with the reports of Karacaören et al. (2006), Buttchereit et al. (2011), and Manzanilla-Pech et al. (2014a), which showed lower and in some cases negative correlations between distant stages of lactation. To the contrary, other studies have reported low but positive genetic correlations between DMI at early- and mid- to latelactation stages (Hüttmann et al., 2009; Liinamo et al., 2012; Tetens et al., 2014; Li et al., 2016). In general, genetic correlations between DMI at different stages of lactation were much lower than unity, and it shows that DMI at the early stages of lactation is a weak predictor of the trait at mid or late stages of lactation. Overall, most of our estimates are in line with the estimates of

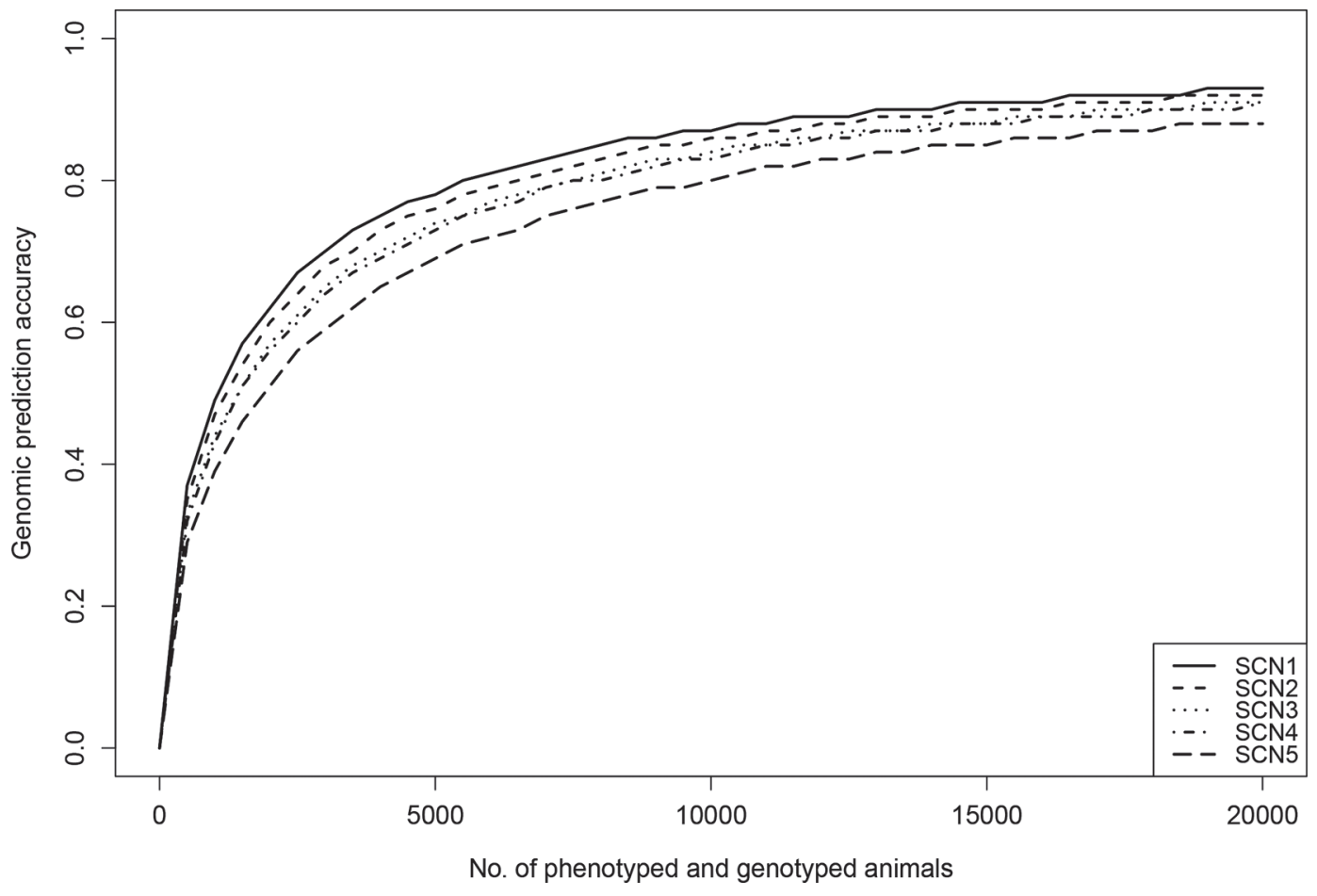

Figure 4. The size of the reference population and the associated genomic prediction accuracy in selection candidates for the different DMI sampling scenarios: SCN1 = recording once every week; SCN2 = recording once every month; SCN3 = recording once every 2 mo; SCN4 = recording once every $3 \mathrm{mo}$; and SCN5 = recording once every 4 mo. The accuracies were calculated after Daetwyler et al. (2008, 2010) and Erbe et al. (2011). 
parameters reported in the literature. The better data and pedigree structure may have contributed to this. However, because the data used in this study are relatively small, verifying the estimates on a much larger data set would be advisable.

\section{Reliability of EBV for DMI, RFI, and ECE Traits}

Unlike other farm animal species, selection for biological efficiency of feed utilization in dairy cows is a difficult task. This is mainly due to the fact that dairy cows pose a particularly challenging problem because of the need to balance the competing processes of lactation, reproduction, health, maintenance, and (in young cows) growth (Weigel, 2013). In addition, dairy cows sustain their high milk yield through intense use of body tissue stores of energy in early lactation and replenish those stores during late lactation. So far, genetic selection in dairy cattle has focused on and resulted in marked improvements in production and reasonable progress in functional traits. The next frontier of genetic selection for dairy cows is therefore the improvement of the biological efficiency of feed utilization, a trait for which cost-effective tools and strategies have been lacking (Weigel, 2013). As a consequence, to improve FE through selection, the discussion about which trait(s) to consider in dairy cattle breeding has recently been a central point. Although different FE traits have been suggested, almost all are dependent on DMI data, and identifying an optimal recording strategy is a crucial point on the way forward.

In this study, the aim was to ascertain by how much the reliability of EBV for DMI and FE traits decrease as the DMI data get sparser with the varying interval and frequency of recording and the associated dwindling number of observations collected per animal. The result in Table 3 showed that for DMI moving from SCN1 to SCN5, the sampling interval increased, the number of observations collected per animal decreased, and, as a result, the reliability of EBV for DMI declined. A similar trend was observed for the RFI and ECE traits. In general, with each increase in the interval of DMI recording, the reliability of EBV decreased by 1.0 to $5.0 \%$ for DMI, 1.0 to $12.0 \%$ for RFI, and 4.0 to $5.0 \%$ for ECE. For all these traits, Table 3 shows that the decline in reliability was faster after SCN3. After SCN4, however, the ability to capture representative DMI samples during lactation and the viability of such less-frequent recording scenarios (SCN4 and SCN5) are somewhat questionable.

It is important to note that several studies, including our study, showed that genetic correlations between DMI at different stages of lactation are much less than unity (Karacaören et al., 2006; Hüttmann et al., 2009;
Buttchereit et al., 2011; Liinamo et al., 2012; Tetens et al., 2014; Li et al., 2016). In fact, except for the correlations within mid-lactation stages, correlations with the other stages and particularly between the early and late stages of lactation are low and close to zero, implying that DMI at different stages of lactation are indeed different traits (Karacaören et al., 2006; Buttchereit et al., 2011; Manzanilla-Pech et al., 2014a). Therefore, the best recording strategy should be the one that captures DMI records on days that are representative of the different stages of lactation. Nevertheless, recording DMI for a certain period of lactation (e.g., mid lactation) requires continuous on-farm recording (given that cows are calving year-round). One other potential problem associated with longer continuous recording is that it will be limited to specific stages of lactation and thus it may not be able to accurately predict DMI at other stages. Breeding values estimated on the basis of such data would therefore result in lower accuracies, especially when such estimates are used to infer about the whole lactation. The other shortcomings of limiting DMI recording to only a specific period during lactation are that the size of comparison groups would be reduced significantly, applying a 15-wk period would reduce the size of the contemporary group to one-third, and that DMI recording would have to be carried out continuously on the farm to get records from all cows. In general, the scenarios tested in this study were designed to record DMI on-farm from most representative stages of lactation. The length of DMI recording intervals varied between different scenarios. Shorter intervals can be expected to be much more demanding and costly but result in higher throughput of DMI phenotypes than the longer recording intervals. As a consequence, the resulting accuracies of EBV varied.

\section{Evaluation of Recording Scenarios Under Varying Levels of Reliability of Sire EBV}

Results in Table 4 show that adopting a scenario with a relatively less-frequent recording interval but with a somewhat increased number of cows measured is preferable over the use of the most frequent and expensive DMI recording scenarios, such as SCN1. For instance, a sire reliability of 0.8 was achieved for SCN1 when DMI recording was done once weekly and a sire had 46 daughters measured with about 34 observations recorded per lactation from each of his daughters (total of 1,596 observations per sire). When SCN1 was compared with SCN2, the same level of reliability (0.8) was achieved with just 7 more daughters recorded per sire above that required for SCN1. This resulted in a reduction in the number of observations to be collected per animal and hence marked savings in time 
and money required for sample collection. However, in terms of frequency, with a recording interval of 1 mo, SCN2 is a bit closer to that of weekly recording (SCN1). Thus, perhaps the most practical advantage comes with the adoption of SCN3, where recording was done once every 2 mo. When SCN3 was compared with SCN1, the same level of reliability of 0.8 was achieved with recording of only 17 more daughters per sire (i.e., total of 63) above that required by SCN1 (i.e., total of 46). In addition to the much-reduced frequency of DMI recording in SCN3 (one-eighth of SCN1), the total number of observations needed decreased markedly by $80 \%$ from 1,596 to 277 DMI observations per sire, leading to a marked reduction in the cost and logistics of DMI collection on-farm. On the other hand, with SCN4, recording DMI on 66 daughters per sire (i.e., 20 more daughters than in SCN1) once every 3 mo (with 3.1 observations recorded per cow) gave the same level of reliability of 0.8 as SCN1. After SCN4, however, the number of daughters to be recorded per sire for a given level of reliability markedly increased, and there was not much reduction in the number of observations to be recorded per sire and in the cost and logistics of data collection. In general, our results show that with the implementation of a less-frequent DMI recording scenario such as SCN3 on-farm, a similar level of reliability as with SCN1 could be realized with the recording of just 17 more daughters per sire (i.e., $37 \%$ more) than the total of 46 per sire for SCN1. In practical terms, the adoption of such a recording strategy (once every $2 \mathrm{mo}$ ) corresponds with the sampling intervals of many of the existing routine milk recording systems for milk compositional traits. This therefore implies great opportunities for synchronizing DMI recording with the routine milk recording systems, leading to harmonizing and simplifying future on-farm data collection.

\section{Genomic Selection}

Dense genome-wide marker maps and genomic prediction have a significant effect on the collection, generation, and use of phenotypes that are difficult and expensive to measure in livestock genetic improvement. Contrary to conventional breeding schemes, genomic selection relaxes the need to collect many phenotypes to achieve genetic progress (de Haas et al., 2017). Instead, genetic progress is conditional on the accuracy of genomic predictions (Meuwissen and Goddard, 2001; Goddard and Hayes, 2009; Hayes et al., 2009) and opens the possibility to efficiently select for traits that are expensive and difficult to measure. For instance, genomic selection is progressively used to increase the rate of genetic progress for production traits that are measured late in life (e.g., meat yield and quality), expensive to measure (e.g., RFI), and are linked to sex (e.g., milk production and quality; Pickering et al., 2015). Feed intake in dairy cows is currently one of the difficult and costly traits to measure routinely in commercial farms. Although few methods are available for on-farm recording of DMI on individual animals, some are still under development (Lassen et al., 2018), whereas others are either expensive or time consuming and tedious and are therefore not suited for large-scale phenotyping. Thus, genomic selection relaxing the need for large-scale phenotyping opens the possibility of including feed intake and efficiency traits in dairy cattle breeding goals.

The effectiveness of genomic selection depends on the size and composition of the reference population used in genomic predictions (Daetwyler et al., 2008; Goddard, 2009). One of the main questions in identifying a low-cost and accurate on-farm DMI intake recording strategy would therefore be to determine how large the reference population has to be - that is, how many animals need to be measured for DMI and genotyped with genome-wide marker panels for each of the different scenarios and what would be the associated accuracy. In this regard, our analysis showed that considering DMI recorded monthly (SCN2) on 4,200 cows would result in a genomic prediction accuracy of 0.6 for DMI. Increasing the reference population to 12,000 cows would increase prediction accuracy to 0.8 . If the recording interval would be decreased to 3 times a year (once every 4 mo; SCN5), the number of recorded cows needed to achieve a genomic prediction reliability for DMI of 0.6 or 0.8 would be about 5,000 and 15,000 , respectively. Under circumstances where recording of DMI is limited to a small cow population, high reliabilities could be achieved at least for sires considering a progeny testing scheme. For instance, recording of DMI on 2,500 cows would allow achieving for 30 to 50 sires a reliability of about 0.8 depending on how often DMI is measured in each cow. Therefore, in general, the indications are that in view of the cost and the logistics involved, the practical implementation of frequent DMI recording scenarios such as SCN1 and SCN2 may be difficult under on-farm situations. Setting up a relatively larger reference population and adopting less-frequent DMI sampling scenarios such as SCN3 would provide high genomic prediction accuracy in selection candidates that is just 5.0 to 7.0 percentage points less than that of the most frequent and expensive sampling scenarios.

\section{Final Remarks}

Rising feed costs and concerns about greenhouse gas emissions and nutrient losses to the environment associated with animal production necessitate identifying the 
most efficient dairy cattle for milk production (Connor et al., 2013). Feed accounts for more than 50 to $60 \%$ of the cost of milk production, and even a small improvement in FE will have a marked effect on increasing farm profitability. For this, accurate and regular monitoring of the nutrient intake of dairy cows is essential. For instance, Basarab et al. (2013) underscored that genetic selection for RFI is highly dependent on accurate measurement of individual animal feed intake. However, as low-cost recording strategies and instruments have not yet been made available, ensuring high throughput and accurate feed intake recordings for national genetic or genomic evaluations for $\mathrm{FE}$ traits has been difficult. It is therefore important to underscore the role that the type of DMI recording techniques and methods plays in developing effective and sustainable recording strategies.

So far available DMI recording techniques range from manual collection over automated feed recording weigh bins to machine vision and video-based techniques (DeVries et al., 2003; Bach et al., 2004; Chizzotti et al., 2015). Most of the conventional techniques have a problem in that they affect the behavior of the animal and compromise the routine farm operations that most farmers may not be content with. With the advance in computing and imaging technology, there are now new applications under development that would help speed up and increase the amount of records collected at a reasonable cost and with less logistical demand. Some examples of this include the electronic system for monitoring individual feeding behavior and feed intake in freestall-housed dairy cattle (Chizzotti et al., 2015; Lassen et al., 2018). The other example is the use of machine vision-structured light illumination 3-dimensional scanning of cow feed to determine the volume and weight of feed in a bin before and after feeding visits by dairy cows (Shelley et al., 2016). In general, such systems are ideal for on-farm implementation because they do not obstruct workflow or cow feeding behavior. This is an improvement over existing systems because these systems could easily be implemented into existing farm operations with minimal effort and cost (Shelley et al., 2016). The most important advantage of such techniques for on-farm DMI collection is their ability for high throughput without any effect either on the behavior of the animals or on routine farm operations. As mentioned earlier, one of the main hindrances for the direct inclusion of FE in dairy cow breeding goals is the difficulty and costs associated with acquiring individual animal feed intake measurements (Veerkamp, 1998). Therefore, future studies on DMI recording in commercial farms should be supported with actual cost and economic valuation for accurate and comprehensive evaluation.
Today, the advent of genomic selection and high-density SNP panels has made it possible to genotype large numbers of animals at a reasonable cost. Consequently, genomic prediction is feasible even for most traits that are expensive and difficult to measure in dairy cattle. Even with this approach, setting a reasonably sized reference population requires careful consideration of the different DMI recording strategies and the expected accuracy of genomic prediction, and thus results from this study can be a useful guide. In the interim, to improve $\mathrm{FE}$, the use of all available DMI registrations along with easily available production and BW measurements in genomic predictions would be a good step forward. As most of the variation in DMI is due to ECM and metabolic BW, such an evaluation will have a closely similar accuracy whether animals have DMI measured or not. However, it should be cautioned that if such an implementation comes with relatively more weight on $\mathrm{BW}$, it may lead to improvement of FE only by reducing the BW of animals. To circumvent this and to add some power to $\mathrm{FE}$ evaluation, there is a need for more DMI information measured on individual animals, and the strategies set out in this study will serve as a practical guide on the way forward.

\section{CONCLUSIONS}

In this study, genetic correlations between DMI at different stages of lactation were much lower than unity and suggest that recording DMI of animals at representative stages during lactation is essential. Results from the comparison of the $5 \mathrm{DMI}$ recording scenarios showed that compared with the expensive once-weekly recording scenario (SCN1), adopting the $\mathrm{SCN} 3$ scenario (once every $2 \mathrm{mo}$ ) gave the same level of reliability as the weekly recording with just 17 more daughters recorded per sire than the 46 required for SCN1. It also resulted in a marked reduction (by about $80 \%$ ) in the total number of observations to be recorded per sire (from 1,596 in SCN1 to 277 in SCN3). Such a strategy is therefore less demanding logistically and will be low cost in part because fewer records need to be collected per animal. Genomic selection holds a great promise to improve FE traits. Even with this technology the cost and logistics involved with the SCN1 and SCN2 recording scenarios could still prove difficult under onfarm conditions. However, setting up a relatively larger reference population and adopting a less-frequent DMI recording strategy such as SCN3 gave prediction accuracies that were only 5.0 to 7.0 percentage points less than the most frequent (SCN1) and expensive recording strategies. In summary, our results suggest that DMI recording strategies that are sparse in terms of records per cow but with slightly more cows recorded 
per sire are beneficial both in genomic selection and in traditional progeny testing schemes, when accuracy, logistics, and cost implications are taken into account.

\section{ACKNOWLEDGMENTS}

This study was part of the Nordic countries (Denmark, Finland, Norway, and Sweden) joint project on Feed Utilization in Nordic Cattle (FUNC) aimed at improving the utilization of feed resources in Nordic cattle populations. The authors thank the data and financial contributions of the involved countries as well as the direct and indirect technical support of members of the consortium. Particularly, the financial support provided by the Finnish Ministry of Agriculture (DNRO: 1844/312/2012; Helsinki, Finland), Valio Ltd. (Helsinki, Finland), Faba co-op (Vantaa, Finland), VikingGenetics (Randers, Denmark), The Finnish Cattle Breeding Foundation (Hamina, Finland), and RAISIOagro Ltd. (Raisio, Finland) is greatly acknowledged.

\section{REFERENCES}

Ahvenjärvi, S., L. Nyholm, J. Nousiainen, E. A. Mäntysaari, and M. Lidauer. 2018. Polyethylene glycol as an indigestible marker to estimate faecal output in dairy cows. J. Dairy Sci. 101:4245-4258.

Bach, A., C. Iglesias, and I. Busto. 2004. Technical note: A computerized system for monitoring feeding behavior and individual feed intake of dairy cattle. J. Dairy Sci. 87:4207-4209.

Basarab, J. A., K. A. Beauchemin, V. S. Baron, K. H. Ominski, L. L. Guan, S. P. Miller, and J. J. Crowley. 2013. Reducing GHG emissions through genetic improvement for feed efficiency: Effects on economically relevant traits and enteric methane. Animal $7: 303-315$

Berry, D. P., B. Horan, M. O’Donovan, F. Buckley, E. Kennedy, M. McEvoy, and P. G. Dillon. 2007. Genetics of grass dry matter intake, energy balance, and digestibility in grazing Irish dairy cows. J. Dairy Sci. 90:4835-4845.

Buttchereit, N., E. Stamer, W. Junge, and G. Thaller. 2011. Genetic relationships among daily energy balance, feed intake, body condition score, and fat to protein ratio of milk in dairy cows. J. Dairy Sci. 94:1586-1591.

Chizzotti, M. L., F. S. Machado, E. E. L. Valente, L. G. R. Pereira, M. M. Campos, T. R. Tomich, S. G. Coelho, and M. N. Ribas. 2015. Technical note: Validation of a system for monitoring individual feeding behavior and individual feed intake in dairy cattle. J. Dairy Sci. 98:3438-3442. https://doi.org/10.3168/jds.2014-8925.

Coffey, M. P., G. Simm, J. D. Oldham, W. G. Hill, and S. Brotherstone. 2004. Genotype and diet effects on energy balance in the first three lactations of dairy cows. J. Dairy Sci. 87:4318-4326.

Connor, E. E., J. L. Hutchison, H. D. Norman, K. M. Olson, C. P. Van Tassell, J. M. Leith, and R. L. Baldwin. 2013. Use of residual feed intake in Holsteins during early lactation shows potential to improve feed efficiency through genetic selection. J. Anim. Sci. 91:3978-3988. https://doi.org/10.2527/jas.2012-5977.

Daetwyler, H. D., R. Pong-Wong, B. Villanueva, and J. A. Woolliams. 2010. The impact of genetic architecture on genome wide evaluation methods. Genetics 185:1021-1031.

Daetwyler, H. D., B. Villanueva, and J. A. Woolliams. 2008. Accuracy of predicting the genetic risk of disease using a genome-wide approach. PLoS One 3:e3395. https://doi.org/10.1371/journal.pone .0003395 .

de Haas, Y., M. Pszczola, H. Soyeurt, E. Wall, and J. Lassen. 2017. Invited review: Phenotypes to genetically reduce greenhouse gas emissions in dairying. J. Dairy Sci. 100:855-870. https://doi.org/ $10.3168 /$ jds.2016-11246.

DeVries, T. J., M. A. G. von Keyserlingk, D. M. Weary, and K. A. Beauchemin. 2003. Technical note: Validation of a system for monitoring feeding behavior of dairy cows. J. Dairy Sci. 86:3571-3574.

Erbe, M., F. Reinhardt, and H. Simianer. 2011. Empirical determination of the number of independent chromosome segments based on cross-validated data. Page 115 in Proceedings of the 62nd Annual Meeting of the European Federation of Animal Science, Stavanger, Norway. Wageningen Academic Publishers, Wageningen, the Netherlands.

García-Cortés, L. A., C. Moreno, L. Varona, and J. Altarriba. 1995. Estimation of prediction-error variances by resampling. J. Anim. Breed. Genet. 112:176-182.

Goddard, M. 2009. Genomic selection: Prediction of accuracy and maximization of long term response. Genetica 136:245-257. https: //doi.org/10.1007/s10709-008-9308-0.

Goddard, M. E., and B. J. Hayes. 2009. Mapping genes for complex traits in domestic animals and their use in breeding programs. Nat. Rev. Genet. 10:381-391.

Hayes, B. J., P. J. Bowman, A. J. Chamberlain, and M. E. Goddard. 2009. Invited review: Genomic selection in dairy cattle: Progress and challenges. J. Dairy Sci. 92:433-443.

Hurley, A. M., N. López-Villalobos, S. McParland, E. Lewis, E. Kennedy, M. O'Donovan, J. L. Burke, and D. P. Berry. 2017. Genetics of alternative definitions of feed efficiency in grazing lactating dairy cows. J. Dairy Sci. 100:5501-5514.

Hüttmann, H., E. Stamer, W. Junge, G. Thaller, and E. Kalm. 2009. Analysis of feed intake and energy balance of high-yielding first lactating Holstein cows with fixed and random regression models. Animal 3:181-188.

Karacaören, B., F. Jaffrézic, and H. N. Kadarmideen. 2006. Genetic parameters for functional traits in dairy cattle from daily random regression models. J. Dairy Sci. 89:791-798.

Koch, R. M., L. A. Swiger, D. Chambers, and K. E. Gregory. 1963. Efficiency of feed use in beef cattle. J. Anim. Sci. 22:486-494.

Korver, S. 1988. Genetic aspects of feed intake and feed efficiency in dairy cattle: A review. Livest. Prod. Sci. 20:1-13.

Lassen, J., J. R. Thomasen, R. H. Hansen, G. G. B. Nielsen, E. Olsen, P. R. B. Stentebjerg, N. W. Hansen, and S. Borchersen. 2018. Individual measure of feed intake on in-house commercial dairy cattle using 3D camera system. In Proceedings of the 11th World Congress of Genetics Applied to Livestock Production, Auckland, New Zealand. Accessed Jul. 28, 2018. http://www.wcgalp .org/proceedings/2018/individual-measure-feed-intake-house -commercial-dairy-cattle-using-3d-camera.

Li, B., B. Berglund, W. F. Fikse, J. Lassen, M. H. Lidauer, P. Mäntysaari, and P. Løvendahl. 2017. Neglect of lactation stage leads to naive assessment of residual feed intake in dairy cattle. J. Dairy Sci. 100:9076-9084.

Li, B., W. F. Fikse, J. Lassen, M. H. Lidauer, P. Løvendahl, P. Mäntysaari, and B. Berglund. 2016. Genetic parameters for dry matter intake in primiparous Holstein, Nordic Red, and Jersey cows in the first half of lactation. J. Dairy Sci. 99:7232-7239.

Li, B., W. F. Fikse, P. Løvendahl, J. Lassen, M. H. Lidauer, P. Mäntysaari, and B. Berglund. 2018. Genetic heterogeneity of feed intake, energy-corrected milk, and body weight across lactation in primiparous Holstein, Nordic Red, and Jersey cows. J. Dairy Sci. 101:10011-10021. https://doi.org/10.3168/jds.2018-14611.

Liinamo, A.-E., P. Mäntysaari, M. H. Lidauer, and E. A. Mäntysaari. 2015. Genetic parameters for residual energy intake and energy conversion efficiency in Nordic Red dairy cattle. Acta Agric. Scand. A Anim. Sci. 65:63-72. https://doi.org/10.1080/09064702 2015.1070897.

Liinamo, A.-E., P. Mäntysaari, and E. A. Mäntysaari. 2012. Short communication: Genetic parameters for feed intake, production, and extent of negative energy balance in Nordic Red dairy cattle. J. Dairy Sci. 95:6788-6794.

Madsen, P., and J. Jensen. 2013. DMU-A package for analyzing multivariate mixed models. Version 6, release 5.2. Center for Quantitative Genetics and Genomics, Department of Molecular Biology and 
Genetics, University of Aarhus Research Centre Foulum, Tjele, Denmark.

Mäntysaari, P., and E. A. Mäntysaari. 2015. Modelling of daily body weights and body weight changes of Nordic Red cows. J. Dairy Sci. 98:6992-7002. https://doi.org/10.3168/jds.2015-9541.

Manzanilla-Pech, C. I. V., R. F. Veerkamp, M. P. L. Calus, J. E. Pryce, and Y. de Haas. 2014a. Genetic parameters and accuracy of recording dry matter intake in first parity Holstein-Friesian cows. Page 554 in Proceedings of the 10th World Congress on Genetics Applied to Livestock Production, Vancouver, BC, Canada.

Manzanilla-Pech, C. I. V., R. F. Veerkamp, M. P. L. Calus, R. Zom, A. van Knegsel, J. E. Pryce, and Y. de Haas. 2014b. Genetic parameters across lactation for feed intake, fat- and protein-corrected milk, and live weight in first-parity Holstein cattle. J. Dairy Sci. 97:5851-5862.

Mason, I. L., A. Robertson, and B. Gjelstad. 1957. The genetic connexion between body size, milk production and efficiency in dairy cattle. J. Dairy Res. 24:135-143.

Mehtiö, T., E. Negussie, P. Mäntysaari, E. A. Mäntysaari, and M. H. Lidauer. 2018. Genetic background in partitioning of metabolizable energy efficiency in dairy cows. J. Dairy Sci. 101:4268-4278.

Meuwissen, T. H., and M. E. Goddard. 2001. Prediction of total genetic value using genome-wide dense marker maps. Genetics 157:1819-1829.

Negussie, E., Y. de Haas, F. Dehareng, R. J. Dewhurst, J. Dijkstra, N. Gengler, D. P. Morgavi, H. Soyeurt, S. van Gastelen, T. Yan, and F. Biscarini. 2017. Invited review: Large-scale indirect measurements for enteric methane emissions in dairy cattle: A review of proxies and their potential for use in management and breeding decisions. J. Dairy Sci. 100:2433-2453. https://doi.org/10.3168/ jds.2016-12030.

Negussie, E., M. Koivula, E. A. Mäntysaari, and M. Lidauer. 2006. Genetic evaluation of somatic cell score in dairy cattle considering first and later lactations as two different but correlated traits. J. Anim. Breed. Genet. 123:224-238.

Pickering, N. K., V. H. Oddy, J. A. Basarab, K. Cammack, B. J Hayes, R. S. Hegarty, J. C. McEwan, S. Miller, C. Pinares, and Y. de Haas. 2015. Invited review: Genetic possibilities to reduce enteric methane emissions from ruminants. Animal 9:1431-1440.

Pryce, J. E., O. Gonzalez-Recio, G. Nieuwhof, W. J. Wales, M. P. Coffey, B. J. Hayes, and M. E. Goddard. 2015. Definition and implementation of a breeding value for feed efficiency in dairy cows. J. Dairy Sci. 98:7340-7350.

Shelley, A. N., D. L. Lau, A. E. Stone, and J. M. Bewley. 2016. Short communication: Measuring feed volume and weight by machine vision. J. Dairy Sci. 99:386-391.
Sjaunja, L. O., L. Baevre, L. Junkkarinen, J. Pedersen, and J. Setälä. 1991. A Nordic proposal for an energy corrected milk (ECM) formula. Pages 156-157 in Performance Recording of Animals: State of the Art, 1990. EAAP Publication no. 50. European Federation of Animal Science, Wageningen, the Netherlands.

Spurlock, D. M., J. C. M. Dekkers, R. Fernando, D. A. Koltes, and A. Wolc. 2012. Genetic parameters for energy balance, feed efficiency, and related traits in Holstein cattle. J. Dairy Sci. 95:5393-5402.

Strandén, I., and M. Lidauer. 1999. Solving large mixed linear models using preconditioned conjugate gradient iteration. J. Dairy Sci. 82:2779-2787.

Tempelman, R. J., D. M. Spurlock, M. Coffey, R. F. Veerkamp, L. E. Armentano, K. A. Weigel, Y. de Haas, C. R. Staples, E. E. Connor, Y. Lu, and M. J. VandeHaar. 2015. Heterogeneity in genetic and non-genetic variation and energy sink relationships for residual feed intake across research stations and countries. J. Dairy Sci. 98:2013-2026.

Tetens, J., G. Thaller, and N. Krattenmacher. 2014. Genetic and genomic dissection of dry matter intake at different lactation stages in primiparous Holstein cows. J. Dairy Sci. 97:520-531.

Vallimont, J. E., C. D. Dechow, J. M. Daubert, M. W. Dekleva, J. W. Blum, C. M. Barlieb, W. Liu, G. A. Varga, A. J. Heinrichs, and C. R. Baumrucker. 2010. Genetic parameters of feed intake, production, body weight, body condition score, and selected type traits of Holstein cows in commercial tie-stall barns. J. Dairy Sci. 93:4892-4901.

Van Arendonk, J. A. M., G. J. Nieuwhof, H. Vos, and S. Korver. 1991 Genetic aspects of feed intake and efficiency in lactating dairy heifers. Livest. Prod. Sci. 29:263-275.

van der Werf, J. H. J., M. E. Goddard, and K. Meyer. 1998. The use of covariance functions and random regressions for genetic evaluation of milk production based on test day records. J. Dairy Sci. 81:3300-3308.

Veerkamp, R. F. 1998. Selection for economic efficiency of dairy cattle using information on live weight and feed intake: A review. J. Dairy Sci. 81:1109-1119.

Veerkamp, R. F., and R. Thompson. 1999. A covariance function for feed intake, live weight, and milk yield estimated using a random regression model. J. Dairy Sci. 82:1565-1573.

Weigel, K. 2013. Will genomic selection be the key to improving feed efficiency in dairy cattle? Accessed Jun. 14, 2018. https://pdfs.semanticscholar.org/bd15/ e7bdf5405cbf201c3bf10dc13677ec0c7d1d.pdf.

Wilmink, J. B. M. 1987. Adjustment of test-day milk, fat and protein yield for age, season and stage of lactation. Livest. Prod. Sci. $16: 335-348$. 